\title{
The Influence and Communication of Chinese Calligraphy in South Korea
}

\author{
Wenjun Zeng ${ }^{1, *}$ \\ ${ }^{1}$ Xiamen Academy of Arts and Design, Fuzhou University, Xiamen, Fujian 361024, China \\ *Corresponding author. Email: $931554083 @ q q . c o m$
}

\begin{abstract}
The discipline construction of Chinese calligraphy is open and inclusive. With the vigorous development in the discipline construction of China's calligraphy, economic prosperity and social stability, the influence and spread of calligraphy in South Korea has become deeper and wider. In this article, data collection and survey methods are mainly used to conduct research. Many aspects of calligraphy thinking, calligraphy media, and calligraphy communication covered by South Korean calligraphy are not only unique, but also complementary to similar disciplines. Therefore, the construction of the calligraphy is of great value in the heterogeneous and isomorphic discipline system. In the process of communication, the art, history, ethnology, and communication will intersect in the calligraphy. This also means that the extensibility and versatility of the calligraphy will exist in all disciplines with vitality that cannot be ignored. However, the communication and influence in South Korea is by no means one-way, nor transplantable. Instead, Chinese calligraphy has emerged from different aspects in the rebuttal and discussion of the South Korean academic circles of calligraphy, with both choices and creations. It is the result of the joint efforts of the calligraphic art scholars of the two countries.
\end{abstract}

Keywords: calligraphy, South Korea, communication

\section{INTRODUCTION}

After the slow development in the last century, Chinese calligraphy has finally inherited from the unconscious into the path of conscious establishment, integration and development. Up to now, there have been changes in the calligraphy competition with neighboring countries.

Japanese school of few characters, the art of engraving calligraphy, and South Korea's adherence to the calligraphy in "Stele of Haotai King" had been popular in China for a time. Up to now, the research is still popular, and China's calligraphy circle has to follow the trend. However, the game of calligraphy has been going on since ancient times. People in China have never stopped learning, communicating and spreading with other countries. For example, as early as the Tang Dynasty, the three Koreas highly praised Ouyang Xun's calligraphy and Li Shimin's calligraphy. And Japan sent Tang envoys to China to study, bringing 300 years of prosperity of Japanese calligraphy.

Nowadays, the construction of calligraphy art in China is booming, which will inevitably have a certain impact on the calligraphy art of neighboring countries. Among them, South Korea is the most abnormal. The whole South Korean calligraphy is promoted under the

opposition to the new Chinese calligraphy, and completes the understanding of China's emerging calligraphy in the process of extremely contradictory refutation and debate. However, this debate and refutation has promoted the communication of Chinese calligraphy in South Korea. Moreover, it has been fully expressed in the aspects of calligraphy education, calligraphy exhibition and calligraphy sales in South Korea, and the way of expression is different from that in China. For example, in the primary education of South Korea, the dissemination of calligraphy is not only based on Yan Zhenqing's calligraphy, but also based on "Zhang Menglong stele", "Longmen statue" and "Zheng Wengong stele", being similar to the undergraduate education courses of calligraphy in China. The most interesting thing is that the communication of calligraphy in South Korea is very prominent in the major film and television dramas. The protagonist in the play either does not make a move, or does well in the calligraphy of Wei and Jin Dynasties, or even make the popular calligraphy of big characters, making people admire. It can be said that the South Korean calligraphy circles are "sharp-minded" in the opposition and debate of Chinese calligraphy, making the calligraphy in South Korea has a lofty character.

For South Korea, the most difficult thing in the process of opposition and refutation is to be "sharp- 
minded". The ultimate expression of "lofty character" is different from the current Chinese calligraphy phenomenon. This kind of "lofty character" is not fierce, tough, and unchanging. It is more advanced in a different face, another kind of speech and another form. Of course, this is related to the local social situation, national psychology and regional ecology in South Korea.

Specifically, the influence and communication of Chinese calligraphy in South Korea are as follows

\section{THE INFLUENCE AND COMMUNICATION OF CHINESE CALLIGRAPHY IN SOUTH KOREA'S EDUCATION OF CALLIGRAPHY}

South Korea retains the calligraphy from primary education to higher education.

Before the dynasty of King Sejong the Great, the literature was written in Chinese, and there had always been a tradition of calligraphy. Among all levels of education in South Korea, primary and secondary schools invest more in calligraphy education. The students in South Korea are not only required to learn Chinese, but also are trained with the foundation of calligraphy.

In South Korea's primary and secondary education, the basic practice of calligraphy lies in the practice of Kai in Tang Dynasty (a regular character). However, it is not limited to this, but synchronized with the Chinese calligraphy education, involving a large number of stele calligraphy, and will not be limited to the calligraphy practice for primary and secondary school students. In addition to the training of Chinese calligraphy, Korean calligraphy is also cultivated. However, all the educators who teach calligraphy still think that Chinese writing is more in line with South Korean tradition, and Chinese character writing is also a symbol of their cultural spirit.

As for the art foundation of calligraphy, regular script is a conventional entry-level font, as is South Korea. The basic calligraphy practice of regular script is based on the regular script of Tang Dynasty, supplemented by the regular script of northern Wei Dynasty, which is basically the same as that in China. The difference is that most of the calligraphy education of the regular script of Tang Dynasty in South Korea starts with the stele calligraphy. Although it learns Yan font appearance of Yan Zhenqing, the calligraphy style is the special brush technique of stele of Wei Dynasty. Especially, it focuses on the practical style.

Therefore, those who write regular script of Tang Dynasty must start with large characters, and then they can understand the essence of reverse front writing. This is a difference from the elementary education of Chinese calligraphy. At the same time, in the practice of large characters, special emphasis is placed on the slow and unsophisticated feeling shown by the natural writing of the brush, focusing on the expression of its character. After such practice, calligraphy works with large characters displayed in various parts of South Korea are more popular, and the calligraphy of plaques such as "千客万来" and "义理同一" can be seen everywhere.

The construction of calligraphy discipline in China starts with the calligraphy education in universities, and gradually covers the primary and secondary school system, so as to be further integrated into the Chinese calligraphy education system. Therefore, compared with South Korea, the construction of calligraphy discipline in Chinese universities is relatively complete.

However, the calligraphy education in South Korea is relatively scarce.

In the famous national universities of South Korea, calligraphy is rarely set up. On the other hand, some private universities with strong comprehensive strength and lively teaching ideas highly praise calligraphy. For example, Gyeonggi University, Daejeon University and Wonkwang University of South Korea have established calligraphy majors. In the main teaching system of calligraphy, there is not only undergraduate education, but also postgraduate and doctoral education. Among them, postgraduate education and doctoral education are particularly prominent, which are also the efforts made by South Korea to read historical documents that can't be understood in this region. Obviously, the calligraphy education in South Korean universities has learned a lot from the calligraphy discipline of Chinese universities. Basically, it involves the art of big-seal character, small-seal character, inscriptions on ancient bronzes and stone tablets, bamboo slips, regular script, official script, running script and cursive script. However, it emphasizes the read of the inscriptions on ancient bronzes and stone tablets, bamboo slips and official script, while regular script and running script are generally regarded as the main aspects of artistic creation of calligraphy. Among them, the research on the stele calligraphy is particularly preferred, and the relevant research results of colleges and universities are also more prominent. As a result, the emphasis of calligraphy education in South Korean universities is different from that of Chinese universities, and there are also some choices in discipline construction and planning.

\section{THE INFLUENCE AND COMMUNICATION OF CHINESE CALLIGRAPHY IN SOUTH KOREA'S DAILY LIFE SUCH AS ADVERTISEMENT AND POSTER}

Calligraphy has its openness, and it is easy to highlight its value and significance in interdisciplinary. 
In the construction of Chinese calligraphy discipline, book and stele calligraphy study have long been included in it and studied as an important subject. Especially, the researches about stele are very important. In the past century, it is closely related to exegetics, philology and art. Such a discipline system has a profound impact on the creation and research of calligraphy in South Korea. It is said that there are many researches of stele calligraphy in different places. However, in daily life, in addition to the display of calligraphy and the expression of calligraphy creation, it does not have much influence in the daily economic life.

In South Korea, the application of the stele calligraphy is more reflected in the daily life such as advertisements, posters and some multimedia visual communication. From the store signs, product trademarks and advertising signs in the streets, it is easy to see the stele character design. These characters are not necessarily written in Chinese characters, but are often designed and written in Korean characters. In other words, the writing method of Korean characters completely is same as that of stele calligraphy. This is different from restoring the ancient fashion in the film and television media, but is in accordance with the ancient style of writing in multimedia performance. The level is superb, but there is no change.

The value and significance of using tablet calligraphy in advertising and poster painting lies in the application of tablet calligraphy to daily life, which has a certain practical effect in modern society, and makes it rich in the aesthetic feeling of modern life. This is the rebirth of the tablet calligraphy and is undoubtedly one of the important ways to promote tablet calligraphy. Also, it needs more ways to express the openness of calligraphy. However, the practicability of calligraphy in South Korea tends to another direction, which is strongly combined with modern design.

Of course, it is not to say that all calligraphy creation in South Korea has been transferred to modern design. The contemporary calligraphy creation in South Korea does not adhere to the classical traditional calligraphy and advocate innovation as the Japanese few character school, modern school and avant-garde school do. There is no discussion on the art of painting and restoring ancient, and examining ugliness as neoclassical and academic calligraphy in China. However, just like the branches and debates in their geographical school, there are many schools of calligraphy in South Korea. This has encouraged the South Korean region, which is based on the relationship between master and apprentice, with strong sense of "color in the door". In such complex faction ecology, calligraphy with great influence is relatively rare. But they generally follow the ancient law and tend to adopt primitive and simple style of writing. Even with the appearance of new book style, it tends to be inferior under the general comments of classical calligraphy. As a result, both the older generation and the new generation of calligraphers in South Korea tend to learn from the ancient methods, including the writing rules of Korean characters, and try to find a way out in the rules of regular script.

Therefore, whether there are many calligraphy schools or the lack of calligraphy ideas, it is not conducive to the revitalization and development of calligraphy. However, as mentioned above, the design of advertisements, posters and other multi-media exhibitions in modern life in South Korea can draw lessons from the classical calligraphy, which is also a good breakthrough in the development of calligraphy in South Korea.

Undoubtedly, this is different from Chinese calligraphy. However, the combination of traditional calligraphy and modern life is indeed a new phenomenon of calligraphy, which is conducive to the exchange and healthy development of calligraphy.

\section{THE INFLUENCE AND COMMUNICATION OF CHINESE CALLIGRAPHY IN THE EXHIBITION AND EXCHANGE OF CALLIGRAPHY IN SOUTH KOREA}

With the development of modern society, the communication between countries is more and more frequent.

Whether it is official or private, it is the same. For the calligraphy, the easiest and most direct way of expression is the display and exchange of calligraphy works. The achievements of the discipline construction of Chinese calligraphy have been presented to the world more than once, both in China and foreign countries. There are a large number of calligraphic artists in China, and they are also relatively active. The exchange of calligraphy with Japan and South Korea is very frequent.

The main form of calligraphy exhibition and exchange between China and South Korea is mainly calligraphy exhibition, supplemented by academic discussion, and the form is relatively simple.

Although the exchange on the construction of calligraphy discipline has not been developed, it has various forms, and calligraphy artists and calligraphers of the two countries have actively participated in the construction of calligraphy.

First of all, Chinese students or scholars have participated in the undergraduate education, master and doctoral education of South Korea. In the case of Yuanguang University and Daejeon University in South Korea, parts of the Chinese students are enrolled in the 
calligraphy education system. The purpose and significance is to let these students learn and understand the essence of ancient calligraphy in South Korea, and carry out effective learning, so as to understand the different methods and concerns of Chinese calligraphy teaching and South Korean teaching, focusing on inspiration and thinking.

Secondly, South Korean scholars also participated in the construction of Chinese calligraphy discipline. This group of South Korean scholars first went to China to study for master's degree and doctoral degree. Then they carried out calligraphy teaching and calligraphy discipline construction in Chinese universities. For example, Chinese Academy of Fine Arts, Guangxi Academy of Arts, Xiamen University and other universities have professors from South Korea who are engaged in calligraphy teaching and calligraphy discipline construction, and have certain scientific research achievements.

Moreover, the calligraphy education in primary and secondary schools in South Korea is inseparable from the contributions of the international students of two countries. Both Chinese and South Korean students have played a certain role in the calligraphy education in South Korea. This can be seen from the writing habits of students in modern South Korean middle school and the presentation of calligraphy works. In other words, there is no big difference in the basic practice methods and entry points of Chinese and Korean calligraphy, and good results have been achieved.

In addition, there are also frequent exchanges among some calligraphy research associations, calligraphy seminars in South Korea, and calligraphy associations in various places of China. There are cultural exchanges and commercial exhibitions between them, and the forms are also distinctive. These are undoubtedly the boosting force of the discipline construction of Chinese calligraphy, and also effective ways for the dissemination of the discipline achievements of Chinese calligraphy in South Korea.

With the development of China's economy and the vigorous development of the discipline construction of Chinese calligraphy, not only the Chinese research results have increased, but also the overseas theoretical research on calligraphy has made certain achievements. The purpose of the establishment of calligraphy is to reveal the basic law of the development of calligraphy, and grasp the law, so as to maintain the long-term vitality of calligraphy. Then the communication and development of calligraphy is also an important aspect of the development of calligraphy. People should not only study the basic creation law of calligraphy, but also study the development of calligraphy education and calligraphy exchange.

\section{CONCLUSION}

In a word, the construction of Chinese calligraphy discipline itself has broad openness and inclusiveness. Calligraphy thinking, calligraphy media, calligraphy communication and many other aspects covered by the calligraphy not only have their particularities, but also complement each other with similar disciplines. The construction of the calligraphy is of great value in the heterogeneous and isomorphic discipline system. The art, history, ethnology, and communication will intersect in the calligraphy. This also means that the extensibility and versatility of the calligraphy will exist in all disciplines with vitality that cannot be ignored. With the vigorous development of Chinese calligraphy discipline construction, economic prosperity and social stability, the influence and communication of calligraphy discipline in South Korea is becoming deeper and wider. However, the spread and influence in South Korea is not unidirectional, nor transplantable. Instead, in the refutation and discussion of calligraphy art in South Korea, there are different performances, with both choices and creations. It is the result of the joint efforts of the calligraphic art scholars of the two countries. The result of this continuous progress and different features is bound to be the vitality of calligraphy discipline.

\section{References}

[1] Liu Yuanfei, Gao Qian. Analysis of the problems faced by calligraphy in colleges and universities [J], Art Panorama, 2006 (11). (in Chinese)

[2] [Japanese]Heitian Pengxin, translated by Yu Jifan. Outline of Art Theory [M], Jiangsu Fine Arts Publishing House, 2010(5). (in Chinese)

[3] Li Rongyou. Art Theory at a New Starting Point M], Beijing: China Social Sciences Press, 2012. (in Chinese)

[4] Zhou Decong. On Higher Education of Calligraphy [J], Appreciation of Calligraphy, 2011 (2). (in Chinese)

[5] Cui Wanzhu, Politics in the golden age of our culture[M], Stone pillow, 1992

[6] Li Xingtao. Problems and countermeasures of calligraphy in local colleges and universities [J], Chinese Calligraphy, 2016 (10). (in Chinese) 